Published Ahead of Print on December 22, 2021 as 10.1212/WNL.0000000000013251

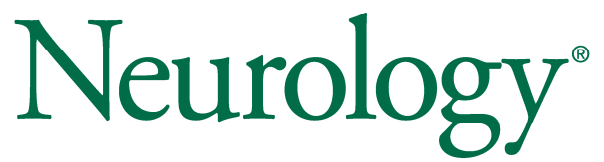

The most widely read and highly cited peer-reviewed neurology journal The Official Journal of the American Academy of Neurology

Neurology Publish Ahead of Print

DOI: 10.1212/WNL.0000000000013251

\title{
Real-time Imaging of Aneurysmal Rupture Causing an Isolated Acute Subdural Hematoma
}

Author(s):

Christopher Hong, MD ${ }^{1}$; Daniela Renedo, MD ${ }^{1}$; Nanthiya Sujijantarat, MD ${ }^{1}$; Andrew Koo, MD ${ }^{1}$; Guido J. Falcone, $\mathrm{MD}^{2}$; Ajay Malhotra, $\mathrm{MD}^{3}$; Nils H. Petersen, $\mathrm{MD}^{2}$; Charles Matouk, MD ${ }^{1,3}$

\section{Corresponding Author:}

Charles Matouk

charles.matouk@yale.edu

Neurology® Published Ahead of Print articles have been peer reviewed and accepted for publication. This manuscript will be published in its final form after copyediting, page composition, and review of proofs. Errors that could affect the content may be corrected during these processes. 
Affiliation Information for All Authors: 1. Department of Neurosurgery, Yale School of Medicine, New Haven, CT; 2. Division of Neurocritical Care and Emergency Neurology, Department of Neurology, Yale School of Medicine, New Haven, CT;3. Department of Radiology, Yale School of Medicine, New Haven, CT

\section{Contributions:}

Christopher Hong: Drafting/revision of the manuscript for content, including medical writing for content; Major role in the acquisition of data; Study concept or design; Analysis or interpretation of data

Daniela Renedo: Drafting/revision of the manuscript for content, including medical writing for content; Major role in the acquisition of data

Nanthiya Sujijantarat: Drafting/revision of the manuscript for content, including medical writing for content; Major role in the acquisition of data

Andrew Koo: Drafting/revision of the manuscript for content, including medical writing for content; Major role in the acquisition of data

Guido J. Falcone: Drafting/revision of the manuscript for content, including medical writing for content; Major role in the acquisition of data; Analysis or interpretation of data

Ajay Malhotra: Drafting/revision of the manuscript for content, including medical writing for content; Major role in the acquisition of data; Analysis or interpretation of data

Nils H. Petersen: Drafting/revision of the manuscript for content, including medical writing for content; Major role in the acquisition of data; Study concept or design; Analysis or interpretation of data

Charles Matouk: Drafting/revision of the manuscript for content, including medical writing for content; Major role in the acquisition of data; Study concept or design; Analysis or interpretation of data

Number of characters in title: 83

Abstract Word count:

Word count of main text: 100

References: 2

Figures: 1

Tables: 0

Neuroimage Legend Count: 50

Supplemental: Consent-to-disclose form CARE checklist

Search Terms: [ 2 ] All Cerebrovascular disease/Stroke, [ 7 ] Intracerebral hemorrhage, [ 8 ] Subarachnoid hemorrhage, [120] MRI

Study Funding: The authors report no targeted funding

Disclosures: The authors report no disclosures relevant to the manuscript. 


\section{MANUSCRIPT}

A 51-year-old woman with hypertension presented with a 3-week history of progressive, right cranial nerve III palsy and headache. During her emergency department evaluation and while in the MRI scanner, she became acutely unresponsive. MRI captured a rapidly expanding acute subdural hematoma (aSDH) (Figure 1). She was emergently taken for decompressive craniectomy. Post-operative imaging demonstrated a ruptured right-sided posterior communicating artery aneurysm.

Isolated aSDH from aneurysmal rupture has previously been reported, but remains underappreciated. ${ }^{1,2}$ Given the dynamic documentation with brain MRI, this case uniquely captures the real-time rupture of an aneurysm directly into the subdural space without associated subarachnoid or intracerebral hemorrhage.

\section{FIGURE LEGEND}

Figure 1. Peri-operative imaging. (A) Normal MRI (localizer) prior to aneurysmal rupture. (B) T2-weighted MRI (axial) showed rapid aSDH enlargement over 5 and (C) 11 minutes into MRI acquisition. (D) Post-craniectomy CT (coronal) showed subtemporal aSDH extension. (E) CTA (coronal) and (F) cerebral angiogram (AP) demonstrated a ruptured posterior communicating artery aneurysm. 

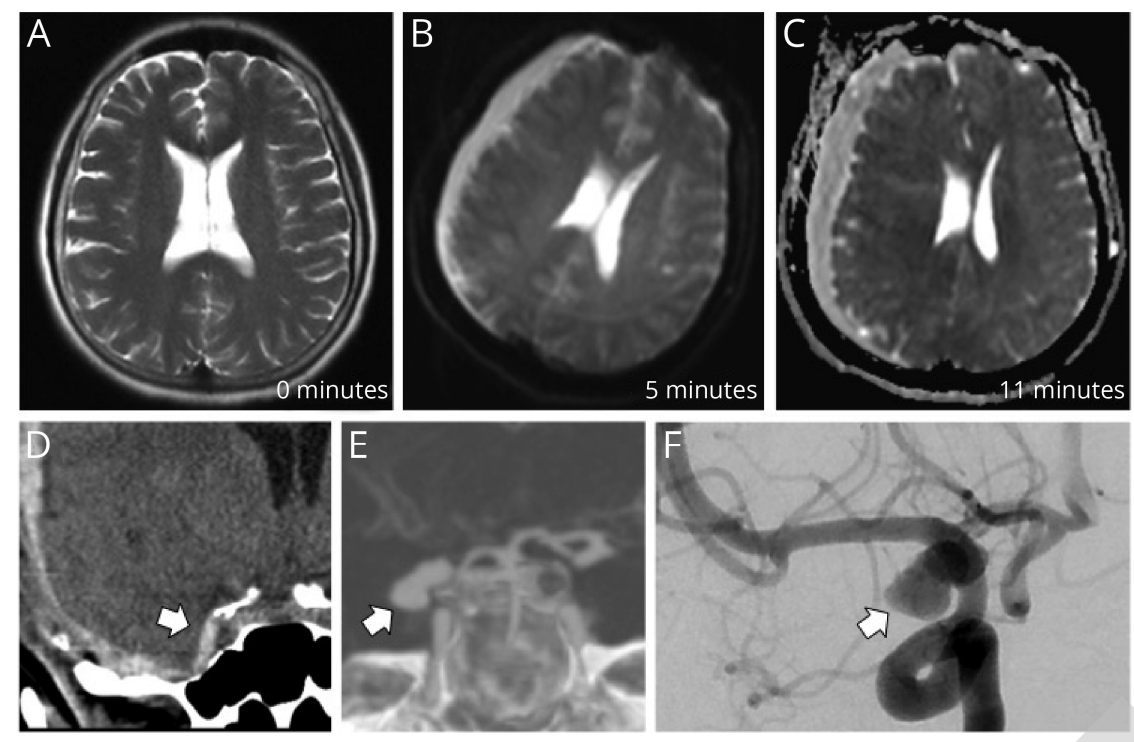

\section{REFERENCES}

1. Mrfka M, Pistracher K, Augustin M, Kurschel-Lackner S, Mokry M. Acute subdural hematoma without subarachnoid hemorrhage or intraparenchymal hematoma caused by rupture of a posterior communicating artery aneurysm: case report and review of the literature. J Emerg Med 2013;44:e369-373.

2. Kondziolka D, Bernstein M, ter Brugge K, Schutz H. Acute subdural hematoma from ruptured posterior communicating artery aneurysm. Neurosurgery 1988;22:151-154. 


\title{
Neurology
}

\author{
Real-time Imaging of Aneurysmal Rupture Causing an Isolated Acute Subdural \\ Hematoma \\ Christopher Hong, Daniela Renedo, Nanthiya Sujijantarat, et al. \\ Neurology published online December 22, 2021 \\ DOI 10.1212/WNL.0000000000013251
}

This information is current as of December 22, 2021

Updated Information \&

Services

Subspecialty Collections

Permissions \& Licensing

Reprints including high resolution figures, can be found at:

http://n.neurology.org/content/early/2021/12/22/WNL.0000000000013251. citation.full

This article, along with others on similar topics, appears in the following collection(s):

All Cerebrovascular disease/Stroke

http://n.neurology.org/cgi/collection/all_cerebrovascular_disease_stroke Intracerebral hemorrhage

http://n.neurology.org/cgi/collection/intracerebral_hemorrhage

MRI

http://n.neurology.org/cgi/collection/mri

Subarachnoid hemorrhage

http://n.neurology.org/cgi/collection/subarachnoid_hemorrhage

Information about reproducing this article in parts (figures,tables) or in its entirety can be found online at:

http://www.neurology.org/about/about_the_journal\#permissions

Information about ordering reprints can be found online:

http://n.neurology.org/subscribers/advertise

Neurology ${ }^{\circledR}$ is the official journal of the American Academy of Neurology. Published continuously since 1951, it is now a weekly with 48 issues per year. Copyright (C) 2021 American Academy of Neurology. All rights reserved. Print ISSN: 0028-3878. Online ISSN: 1526-632X.

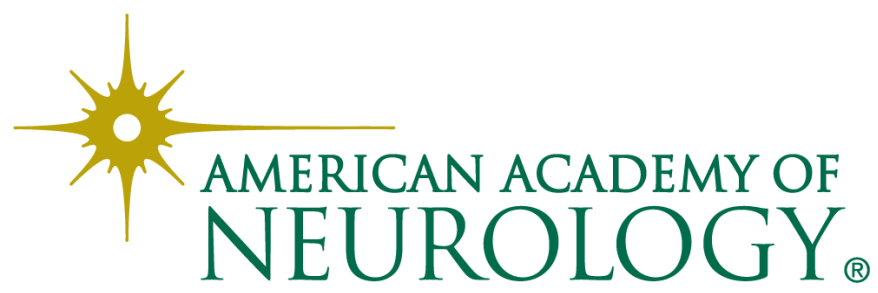

